Andrea Casati MD, Guido Fanelli MD, Marco Berti MD, Paolo Beccaria MD, Massimo Agostoni MD, Giorgio Aldegheri MD, Giorgio Torri $M D$

\title{
Cardiac performance during unilateral lumbar spinal block after crystalloid preload
}

Purpose: The haemodynamic effects of crystalloid preload were evaluated in a randomised blind study in 20 ASA status I-1I, 50-80 yr-old patients, undergoing unilateral spinal anaesthesia for leg surgery produced with low doses of hyperbaric bupivacaine.

Methods: Baseline non-invasive blood pressure (oscillometry), heart rate. stroke volume and cardiac index (transthoracic electrical bioimpedance) were recorded. Then, patients were randomly allocated to receive 10 $\mathrm{ml} \cdot \mathrm{kg}^{-1}$ Ringer's Lactate solution over $20 \mathrm{~min}$ (preload group, $\mathrm{n=10}$ ) or no crystalloid infusion (no-preload group. $n=10$ ). Spinal block was performed using $8 \mathrm{mg}$ hyperbaric bupivacaine $0.5 \%$ injected slowly at the $L_{2}-L_{3}$ interspace $\left(0.02 \mathrm{ml} \cdot \mathrm{sec}^{-1}\right.$ through a 25 -gauge Whitacre needle) with patients lying on their operated side and with the needle opening directed towards the dependent side. Lateral decubitus position was maintained for up to 15 min after anaesthetic injection to facilitate hyperbaric bupivacaine distribution towards dependent regions of the subarachnoid space. Haemodynamic variables were recorded 5, 10, 15 and $30 \mathrm{~min}$ after spinal injection, while sensory level and motor block were evaluated 10, 15 and 30 min after anaesthetic injection on both operated and unoperated side. Results: No differences of upper sensory level and motor block were observed between the two groups on the operated and non-operated sides. Diastolic blood pressure was decreased compared with baseline in the nopreload group only $(P=.0001)$. Systolic arterial pressure and heart rate did not change in either group. Stroke volume and cardiac index were decreased in the no-preload group compared with both baseline $(P=.02$; $P=.001)$ and the preload group $(P=.04 ; P=.02)$.

Conclusion: Crystalloid preload influences cardiovascular function during spinal block, and may be useful when very low bupivacaine doses and lateral decubitus are used to achieve unilateral spinal block.

Objectif : Les effets hémodynamiques de la précharge aux cristalloïdes ont été évalués au cours d'une étude aléatoire à double insu chez 20 patients de 50 à 80 ans ASA I et II soumis à une rachianesthésie hyperbare avec de faibles doses de bupivacaine pour un chirurgie du membre inférieur.

Méthodes : Les valeurs initiales de la pression artérielle non invasive (oscillométrie), de la fréquence cardiaque, du volume d'éjection et de l'index cardiaque (par bioimpédance transthoracique électrique) ont d'abord été enregistrées. Les patients répartis en deux groupes ont reçu $10 \mathrm{ml} / \mathrm{kg}^{-1}$ d'une solution de lactate de Ringer sur une période de $20 \mathrm{~min}$ (groupe précharge, $n=10$ ) ou aucun cristallö̈de (groupe sans précharge, $n=10$ ). La rachianesthésie a été réalisée avec $8 \mathrm{mg}$ de bupivacaỉne hyperbare $0.5 \%$ injectée lentement à $\mathrm{L} 2-\mathrm{L} 3\left(0.02 \mathrm{ml} / \mathrm{sec}^{-1}\right.$ à travers une aiguille Whitacre $25 \mathrm{G}$ ) en position latérale sur le côté opéré avec l'orifice de l'aiguille dirigé vers le bas. La position de décubitus latéral a été maintenue pendant $15 \mathrm{~min}$ après l'injection de l'anesthésique pour favoriser la distribution hyperbare de la bupivacaine vers les régions déclives de l'espace sous-arachnoïdien. Les variables hémodynamiques ont été enregistrées $5,10,15$ et $30 \mathrm{~min}$ après linjection et les niveaux sensitifs et moteurs évalués dans les deux hémicorps 10, 15 et 30 min après l'injection de l'anesthésique.

Résultats : Aucune différence n'a été observée en ce qui concerne le bloc sensitivomoteur entre les deux groupes que ce soit du côté de l'opération ou de l'autre côté. La pression diastolique baissait comparativement à la ligne de base dans le groupe sans précharge seulement $(P<0,0001)$. La pression artérielle systolique et la fréquence cardiaque sont demeurées les mêmes dans les deux groupes. Le volume d'éjection et l'index cardiaque diminuaient dans le groupe sans précharge comparativement aux valeurs de base $(P=0.02 ; P=0.001)$ et au groupe précharge $(P=0,04 ; P=0.02)$.

Conclusion : La précharge aux cristalloïdes influence la fonction cardiovasculaire pendant la rachianesthésie et peut être utile quand de très faibles doses de bupivacaïne sont administrées en association avec le décubitus latéral pour produire une rachianesthésie unilatérale.

From the Department of Anaesthesiology and Intensive Care, University of Milan, IRCCS H San Raffaele, via Olgettina 60 - 20132 Milan (Italy) Address correspondence to: Dr. A. Casat, Phonc: $+39+2+26432656$; Fax: $+39+2+26412823$; E-mail: grifone@rsisi.hsr.it Accepted for publication March 6, 1997. 
$\mathrm{H}$ YPOTENSION and bradycardia are frequent side effects of spinal anaesthesia occurring in up to $30 \%$ of patients. ${ }^{1}$ Various techniques have been described to restrict the extent of somatic and sympathetic spinal block to the operative site, and minimise the risk of hypotension. ${ }^{2-4}$ Very stable arterial blood pressure has been reported during unilateral spinal anaesthesia, probably due to limited sympathectomy and efficient homeostatic vascular mechanisms in non blocked areas that compensate for vasodilatation in one leg. ${ }^{3,4}$ Also, haemodynamic changes during hyperbaric bupivacaine spinal anaesthesia are related to total anaesthetic dose. ${ }^{5}$

The usefulness of crystalloid preload to reduce the incidence and severity of hypotension has been widely discussed. ${ }^{6-13}$ The aim of the present study was to investigate, in patients without a history of heart disease, global cardiac performance during unilateral lumbar spinal block. In addition, cardiovascular changes during restricted spinal block were measured both with and without crystalloid preload, to evaluate the influence of volume loading.

\section{Methods}

Twenty 50-80 yr-old patients, ASA physical status I-II, requiring spinal anaesthesia for elective orthopaedic leg surgery were studied. Hospital Ethics Committee approval was obtained before commencing the study and informed consent was obtained from each patient. Patients with a past history of cardiac or pulmonary disease, with tachyarrhythmias, ECG alterations (e.g., bundle branch block), or ASA physical status >II were excluded from the study.

Patients were studied following an eight hour fast, as is routine in our hospital. No premedication or prophylactic vasoconstrictors were given. After entering the operating theatre, baseline haemodynamic variables were recorded.

Non-invasive systolic (SAP) and diastolic (DAP) arterial pressure were measured using an automated cuff (Dinamap 1846SX, Critikon, Florida, USA). Cardiac output was measured non-invasively by means of Transthoracic Electrical Bioimpedance (TEB) using four electrodes connected to an impedance cardiograph according to the manufacturer instructions (IPG 104 Akern/RJL Systems R\&D, Florence, Italy). Two disposable ECG electrodes were placed on patients' foreheads and gluteus muscles; two other disposable aluminized strip electrodes were attached to the neck posteriorly $\left(7^{\text {th }}\right.$ cervical vertebral spine) and $25 \mathrm{~cm}$ caudally (about $11^{\text {th }}$ dorsal vertebral spine). The length of the two inner electrodes was measured for each patient. The TEB stroke volume (SV) was derived from the Nyboer formula using the backslope projection method. ${ }^{14}$
Cardiac output was calculated from the product of the mean SV over six to ten consecutive heart beats and the simultaneously measured heart rate, derived from continuously recorded ECG. Data were indexed to the patients' body surface area. Continuous ECG and thoracic impedance were recorded on a two-channel heated pen chart recorder at $25 \mathrm{~mm} \cdot \mathrm{sec}^{-1}$. The method used to derive cardiac output has been presented elsewhere. ${ }^{14}$

Using a randomization table patients were allocated to receive $10 \mathrm{ml} \cdot \mathrm{kg}^{-1}$ Ringer's lactate solution over $20 \min$ (Group A; $\mathrm{n}=10$ ) or no crystalloid infusion (Group B; $\mathrm{n}=10$ ).

Patients were then positioned in the lateral decubitus position with the side to be operated upon dependent and the vertebral column was kept as horizontal as possible by tilting the table or putting a cushion under the shoulder. Subarachnoid puncture was performed at the $\mathrm{L}_{2}-\mathrm{L}_{3}$ interspace using the midline approach with a 25 -gauge Whitacre spinal needle (Becton-Dickinson, New Jersey, USA) and the opening directed towards the dependent side of the spinal canal. After free flow of cerebrospinal fluid was observed, $8 \mathrm{mg}$ hyperbaric bupivacaine $0.5 \%$ (heavy Marcaine - Astra, Sweden) was slowly injected without barbotage with an injection speed of approximately $0.02 \mathrm{ml} \cdot \mathrm{sec}^{-1}$ (total anaesthetic dose was injected over $80 \mathrm{sec}$ ). The lateral decubitus position was maintained for up to $15 \mathrm{~min}$ after bupivacaine spinal injection to facilitate anaesthetic solution distribution towards the dependent regions of the subarachnoid space. ${ }^{3,4}$ Then, the patient was turned back to the supine position.

Haemodynamic variables were recorded 5, 10, 15, and $30 \mathrm{~min}$ after local anaesthetic injection. At 10, 15, and $30 \mathrm{~min}$ after spinal puncture, motor blockade (modified Bromage scale), ${ }^{15}$ and upper sensory level (ice test and pinprick test) ${ }^{16}$ on both the operated and non-operated sides were also recorded.

Clinically significant hypotension was defined as a systolic arterial blood pressure decrease of $\mathbf{3 0 \%}$ or more below baseline values. Intravenous colloids (gelatin, $5 \mathrm{ml} \cdot \mathrm{kg}^{-1}$ ) and/or ephedrine $(5 \mathrm{mg}$ ) administration was predetermined as the treatment of clinically significant hypotension.

The physician, who recorded haemodynamic variables as well as sensory level and motor block progression, was unaware whether the patient had received crystalloid preload. Surgery was started after the last measurement was recorded.

Statistical analysis was performed using a statistical software package (Statview 2, Abacus Concepts, Inc., USA). Kruskall-Wallis, Mann-Whitney, and Chisquare tests were used when indicated. A $P$ value $<0.05$ was considered significant. Results are pre- 
sented as mean \pm standard deviation (SD) or median (range) for ordinal data.

The power of the study was assessed using the method described by Glantz. ${ }^{17}$ We wished to detect changes of $0.5 \mathrm{~L}$ between cardiac output data: this value was used for the standardized difference in the power analysis. We used the coefficient of variation of the measured variable, which is a measure of repeatability, for our estimate of standard deviation in the power analysis. For TEB measurements, the reported coefficient of variation for stroke volume and cardiac output is of about $5 \%{ }^{18}$ Based on these figures the required study size was 8 to 11 patients per group.

\section{Results}

The two groups were similar with respect to age, weight, height, body surface area and male to female ratio (Table I). No differences of sensory level or motor blockade on the operated or non-operated side were observed between the two groups. Two patients in Group A and one in Group B showed partial anaesthesia on the non-operated leg after return to the supine position. The other patients showed unilateral distribution of spinal anaesthesia without signs of analgesia or motor block on the non-operated limb, even after being turned back to the supine position.

The final upper sensory level on the operated side was not different in the two groups: respectively $T_{10}$ $\left(T_{12}-T_{8}\right)$ in Group A and $T_{11}\left(T_{12}-T_{8}\right)$ in Group B (Table II). Quality and onset time of motor blockade were not different between groups (Table II): in all patients complete motor blockade on the operated leg developed within $15 \mathrm{~min}$ of spinal puncture. The three patients showing signs of bilateral block, developed complete motor block on the operated side but only partial motor block (Bromage score 1-2) on the non-operated side, and had an upper sensory level on the non-operated side three to five dermatomes below that observed on the operated side.

No clinically significant hypotension was observed during the study, and none of the patients required $i v$ bolus administration of colloids or ephedrine. Systolic and diastolic arterial pressure showed no changes during the study in group A compared with baseline (Figure 1). In Group B, diastolic arterial pressure was decreased 10, 15 and 30 min after spinal puncture compared with baseline values $(P=.0001)$, with a mean reduction of about $15 \%$ from baseline values (Figure 1). No differences in arterial blood pressure, systolic and diastolic, were observed between the two groups (Figure 1).

Heart rate showed no changes in the two groups during the study $(P=.32)$ (Figure 2). A SVI reduction was found in Group B at 5, 10, and 15 min compared
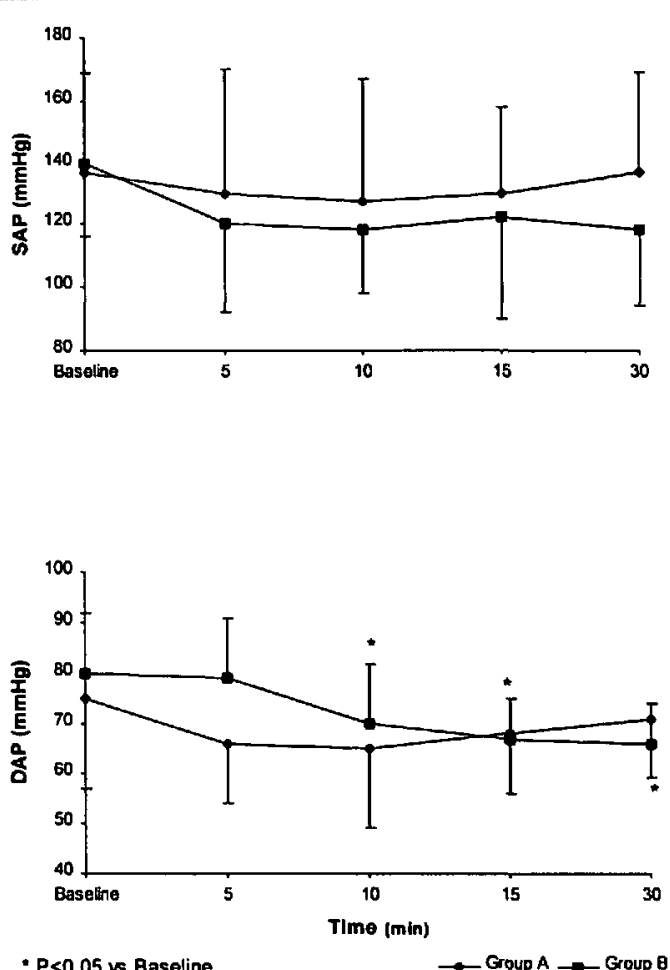

FIGURE I Systolic (SAP), and diastolic (DAP) arterial pressure in patients with (Group A) and withour (Group B) crystalloid preload, measured before i.v. crystalloid infusion (Bascline), and then $5,10,15$, and $30 \mathrm{~min}$ after bupivacaine spinal injection.

TABLE I Demographic data of studied patients

\begin{tabular}{lll}
\hline & Group $A$ & Group B \\
\hline & $(n=10)$ & $(n=10)$ \\
Age $(\mathrm{yr})$ & $62.6 \pm 6.8$ & $60.6 \pm 5.4$ \\
Weight $(\mathrm{kg})$ & $65.6 \pm 3.1$ & $67.7 \pm 4.7$ \\
Height $(\mathrm{cm})$ & $164 \pm 3.1$ & $164 \pm 2.0$ \\
BSA $^{1}\left(\mathrm{~m}^{2}\right)$ & $1.6 \pm 0.05$ & $1.7 \pm 0.06$ \\
Male $/$ Female & $3 / 7$ & $4 / 6$ \\
\hline
\end{tabular}

(Group A = patients receiving crystalloid preload; Group B = patients without preload)

${ }^{1} \mathrm{BSA}=$ body surface area

TABLE II Median (range) sensory level and median (range) motor blockade recorded on the operated and the non-operated sides 10,15 and $30 \mathrm{~min}$ after spinal puncture in patients with (Group A) and without (Group B) crystalloid preload

\begin{tabular}{lll}
\hline & Group $A$ & Groutp $B$ \\
\hline & $(n=10)$ & $(n=10)$ \\
Sensory level 10 min & $\mathrm{T}_{12}\left(\mathrm{~L}_{1}-\mathrm{T}_{10}\right)$ & $\mathrm{T}_{12}\left(\mathrm{~L}_{1}-\mathrm{T}_{10}\right)$ \\
Sensory level 15 min & $\mathrm{T}_{11}\left(\mathrm{~T}_{12}-\mathrm{T}_{8}\right)$ & $\mathrm{T}_{11}\left(\mathrm{~T}_{12}-\mathrm{T}_{10}\right)$ \\
Sensory level 30 min & $\mathrm{T}_{10}\left(\mathrm{~T}_{12}-\mathrm{T}_{8}\right)$ & $\mathrm{T}_{11}\left(\mathrm{~T}_{12}-\mathrm{T}_{8}\right)$ \\
Motor block 10 min & $2(1-2)$ & $2(1-3)$ \\
Motor block 15 min & $3(3-3)$ & $3(2-3)$ \\
Motor block 30 min & $3(3-3)$ & $3(3-3)$ \\
\hline
\end{tabular}



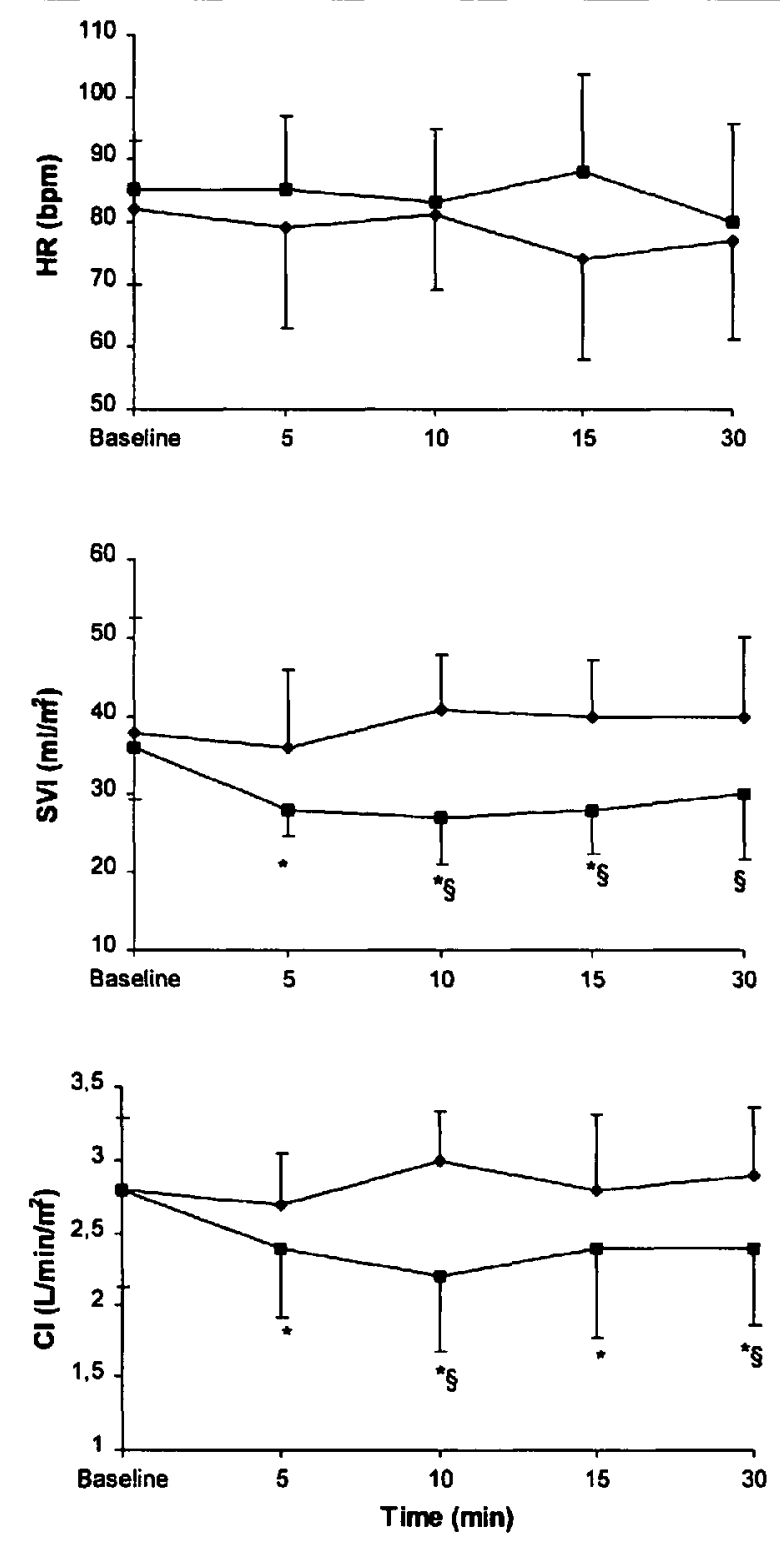

- Pro, 05 vs Basetine 5 $P \infty, 05$ vs Group A

$\rightarrow$ Group A $\rightarrow$ Group B

FIGURE 2 Modifications of heart rate (HR) stroke volume index (SVI), and cardiac index (CI), in patients with (Group A) and without (Group B) crystalloid preload, measured before ip crystalloid infusion (Baseline), and then $5,10,15$, and $30 \mathrm{~min}$ after bupivacaine spinal injection.

with baseline $(P=.02)$, and at 10,15 and $30 \mathrm{~min}$ compared with group A $(P=0.04)$ (Figure 2). Cardiac index was decreased in Group $B$ during the study in respect of baseline $(P=0.001)$, with a reduction of about 15-20\%; but there were no changes in Group A. A decrease in CI was found at 10 and $30 \mathrm{~min}$ after bupivacaine spinal injection in Group $B$ compared with Group A $(P=.02)$ (Figure 2).

\section{Discussion}

The most important finding of the present study is that unilateral spinal anaesthesia performed with low doses of hyperbaric bupivacaine led to decreases in DAP, SVI and $C I$ in patients without crystalloid preload compared with patients receiving a small volume of $i v$ crystalloid (Figures 1 and 2). The rate of onset of sensory and motor blockade, as well as the final sensory level on the operated side, was similar in the two groups.

The clinical importance of SVI and CI decrease found in patients without crystalloid preload might be questioned: none of the patients developed clinically significant hypotension during the study (SAP reduction $>30 \%$ of baseline values). This was not surprising because cardiovascular effects during hyperbaric bupivacaine spinal anaesthesia are related to total anaesthetic dose. ${ }^{5}$ Although we were unable to determine efficacy or cardiovascular safety of unilateral spinal block, because of the small study population, our results agree with previous reports, ${ }^{3,4}$ which demonstrated higher cardiovascular stability during unilateral spinal block by low doses of hyperbaric local anaesthetic than with standard spinal anaesthesia. Unilateral block probably produces less venous pooling and allows a greater part of the body to compensate for blood pooling in blocked areas compared with standard spinal anaesthesia. ${ }^{3,4}$

Some observations should be also made on the technique of cardiac output measurement. Each technique has inherent advantages and disadvantages, and is subject to a margin of error. ${ }^{19}$ The accuracy of cardiac output measurements provided by TEB has been widely discussed..$^{18-23}$ However, even if some consider TEB inaccurate, compared with thermodilution, the accuracy was of limited importance in our study as relative changes were analyzed.

In agreement with others, the results of the present study demonstrated that, even if minimal bupivacaine doses are used, a small volume of crystalloid infusion, administered before the block, influences cardiovascular performance. In an elegant study of left ventricular global and regional function during bilateral epidural anaesthesia up to $\mathrm{T}_{9}$, Baron et al. $^{23}$ demonstrated that left ventricular preload and end-systolic pressure were increased after volume loading both in normal patients and in patients suffering from stable mild effort-related angina.

The importance of crystalloid preload in the management of spinal anaesthesia has been widely discussed. Many studies have concluded that volume loading is a satisfactory method of preventing hypotension. ${ }^{5-10}$ Crystalloids and colloids have been used to compensate for these changes, and arguments 
have been advanced for the use of each. In general, the use of crystalloids requires a larger volume than do colloids. The latter may remain longer in the intravascular compartment, but they are more expensive and may lead to anaphylaxis.

On the contrary, some authors have suggested that crystalloid preload was of little use in the prevention of hypotension during central neural block. ${ }^{711-13}$ Jackson $e t a l .{ }^{11}$ showed that there was no advantage in giving one litre of crystalloid preload compared with $200 \mathrm{ml}$, to reduce the incidence and severity of hypotension after spinal anaesthesia for elective caesarean section. Coe et al..$^{12}$ found that the incidence of hypotension was not different in elderly patients receiving $0.8 \mathrm{ml} \cdot \mathrm{kg}^{-1}$ or $16 \mathrm{ml} \cdot \mathrm{kg}^{-1}$ as volume loading before spinal anaesthesia for lower limb or lower abdominal operations. It must also be remarked that large volumes of fluid may be dangerous, especially in elderly patients with the risk of pulmonary oedema and cardiac failure.

As demonstrated by our results, unilateral spinal block, even if performed with minimal doses of hyperbaric bupivacaine, can lead to considerable reduction in stroke volume and cardiac index in patients who do not receive crystalloid preload before spinal puncture. Stroke volume and cardiac index reduction in patients without preload is probably produced by a decrease of venous return to the heart, which leads to a ventricular leftwards shift on Starling's curve. ${ }^{25}$

Patients in the present study were ASA physical status I and II, and our results may not pertain to patients with cardiac disease. Further studies in elderly patients with co-existing cardiorespiratory disease should be performed. Nevertheless, mild crystalloid preload might provide a further protection against undesired cardiovascular side effects, even when a restricted spinal block is obtained by means of lateral decubitus and very low anaesthetic doses. We believe that our results may have clinical importance for practitioners routinely faced with frail, old patients.

\section{Acknowledgements}

This study was supported by a grant from IRCCS $\mathrm{H}$ San Raffaele - University of Milan. Special acknowledgements to $\mathrm{Dr} T$. Talluri for his helpful suggestions.

\section{References}

1 Moore DC, Bridenbaugh LD. Spinal (subarachnoid) block. A review of 11,574 cases. JAMA 1966; 195: 123-8.

2 Jonnesco T. Remarks on general spinal analgesia. BMJ $1909 ; 2: 1935-40$.
3 Tanasichuk MA, Sbultz EA, Matthews JH, Van Bergen $F H$. Spinal hemianalgesia: an evaluation of a method, its applicability, and influence on the incidence of hypotension. Anesthesiology 1961; 22: 74-85.

4 Fanelli $G$, Casati A, Beccaria P, Agostoni M, Berti $M$, Torri G. Bilateral persus unilateral selective subarachnoid anaesthesia: cardiovascular homeostasis. $\mathrm{Br} \mathrm{J}$ Anaesth 1996; 76: A242.

5 Bridenbaugh PO, Greene NM. Spinal (subarachnoid) neural blockade. In: Cousins MJ, Bridenbaugh PO (Eds.). Neural Blockade in Clinical Anesthesia and Management of Pain, 2nd ed. Philadelphia: Lippincott Company, 1988: 213-51.

6 Wollman SB, Marx GF. Acute hydration for prevention of hypotension of spinal anesthesia in parturients. Anesthesiology 1968; 29: 374-80.

$7 \mathrm{McCrac} A$ F, Wildsmith JAW. Prevention and treatment of hypotension during central neural block. $\mathrm{Br} \mathrm{J}$ Anaesth 1993; 70: 672-80.

8 Lewis $M$, Thomas $P$, Wilkes $R G$. Hypotension during epidural analgesia for Cacsarean section. Anaesthesia 1983; 38: 250-3.

9 Venn PJH, Simpson DA, Rubin AP, Edstrom $H H$. Effect of fluid preloading on cardiovascular variables after spinal anaesthesia with glucose-free $0.75 \%$ bupivacaine. $\mathrm{Br} J$ Anaesth 1989; 63: 682-7.

10 Wennberg E, Frid I, Haljamäe $H$, Wennergren $M$, Kjellmer I. Comparison of Ringer's acetate with 3\% dextran $\mathbf{7 0}$ for volume loading before extradural Caesarean section. Br J Anaesth 1990; 65: 654-60.

11 Jackson R, Reid JA, Thorburn J. Volume preloading is not essential to prevent spinal-induced hypotension at Caesarean section. Br J Anaesth 1995; 75: 262-5.

12 Coe AJ, Revanäs $B$. Is crystalloid preloading useful in spinal anaesthesia in the elderly? Anaesthesia 1990; 45: 241-3.

13 Rout CC, Akoojee SS, Rocke DA, Gouws E. Rapid administration of crystalloid preload does not decrease the incidence of hypotension after spinal anaesthesia for elective Caesarean section. Br J Anaesth 1992; 68: 394-7.

14 Nyboer J. Workable volume and flow concepts of biosegments by electrical impedance plethysmography. T.I.T. Journal of Life Sciences 1972; 2: 1-13.

15 Bromage PR. A comparison of the hydrochloride and carbon dioxide salts of lidocaine and prilocaine in epidural analgesia. Acta Anaesthesiol Scand 1965; 16: 55-9.

16 Liu S, Kopacz DJ, Carpenter RL. Quantitative assessment of differential sensory nerve block after lidocaine spinal anesthesia. Anesthesiology 1995; 82: 60-3.

17 Glantz SA. Primer of Biostatistics, 2nd ed. London: McGraw-Hill, 1988.

18 Jewkes C, Sear JW, Verhoeff F, Sanders DJ, Fö̈x P. Noninvasive measurement of cardiac output by thoracic 
electrical bioimpedance: a study of reproducibility and comparison with thermodilution. Br J Anaesth 1991; 67: 788-94

19 Darovic GO, Yacone-Morton LA. Monitoring cardiac output. In: Darovic GO (Ed.). Hemodynamic Monitoring: Invasive and Noninvasive Clinical Application, 2nd ed. Philadelphia: WB Saunders Company, 1995: 323-46.

20 Bernstein DP. A new stroke volume equation for thoracic electrical bioimpedance: theory and rationale. Crit Care Med 1986; 14: 904-9.

21 Spiess BD, McCarthy RJ, Tuman KJ, Ivankovich $A D$. Bioimpedance hemodynamics compared to pulmonary artery catheter monitoring during orthotopic liver transplantation. J Surg Res 1993; 54: 52-6.

22 Wong DH, Tremper KK, Stemmer EA, et al. Noninvasive cardiac output: simultaneous comparison of two different methods with thermodilution. Anesthesiology 1990; 72: 784-92.

23 Salandin $V$, Zussa $C$, Risica $G$, et al. Comparison of cardiac output estimation by thoracic electrical bioimpedance, thermodilution, and Fick methods. Crit Care Med 1988; 16: 1157-8.

24 Baron J-F, Coriat $P$, Mundler $O$, Fauchet $M$, Bousseau $D$, Viars $P$. Left ventricular global and regional function during lumbar epidural anesthesia in patients with and without angina pectoris. Influence of volume loading. Anesthesiology 1987; 66: 621-7.

25 Guyton $A C$. Regulation of cardiac output. N Engl J Med 1967; 277: 805-12. 